\title{
El Partido Socialista de la Izquierda Nacional (PSIN) de Córdoba durante los años sesenta. Su despliegue organizativo y su gravitación en el Cordobazo
}

\section{[The Socialist Party of the National Left (PSIN) of Córdoba during the Sixties. Its Organizational Deployment and its Gravitation in the Cordobazo]}

\author{
Ernesto Roland \\ (Instituto de Humanidades /Universidad Nacional de Córdoba- \\ Consejo Nacional de Investigaciones Científicas y Técnicas) \\ choloroland@gmail.com
}

Resumen:

A partir de una aproximación a la identidad ideológica de la Izquierda Nacional, este artículo reconstruye la línea política del Partido Socialista de la Izquierda Nacional (PSIN) durante el primer tramo de la "Revolución Argentina"; la conformación de este partido político en Córdoba durante los años sesenta, su inserción en el movimiento estudiantil y su vinculación con el movimiento obrero; la participación de su militancia en el Cordobazo; y el significado que la organización construyó en torno a dicho acontecimiento en el periodo posterior.

Palabras clave: Izquierda Nacional - Partido Socialista de la Izquierda Nacional (PSIN) Cordobazo.

\begin{abstract}
:
From an approach to the ideological identity of the National Left, this article reconstructs the political line of the Socialist Party of the National Left (PSIN) during the first stretch of the "Argentine Revolution"; the formation of this political party in Córdoba during the sixties, its insertion in the student movement and its relationship with the labor movement; the participation of his militancy in the Cordobazo; and the meaning that the organization built around this event in the subsequent period.
\end{abstract}

Keywords: National Left - Socialist Party of the National Left (PSIN) - Cordobazo.

Recibido: 24/09/2019

Evaluación: 25/11/2019

Aceptado: 09/12/2019

Anuario de la Escuela de Historia Virtual - Año 10 - N 16 - 2019: pp. 115-136. ISSN: 1853-7049

http://revistas.unc.edu.ar/index.php/anuariohistoria 


\section{El Partido Socialista de la Izquierda Nacional (PSIN) de Córdoba durante los años sesenta. Su despliegue organizativo y su gravitación en el Cordobazo}

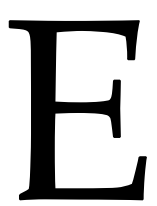

ste artículo explora el Partido Socialista de la Izquierda Nacional (PSIN), una organización política escasamente atendida en los estudios sobre el proceso de radicalización político-ideológica y movilización social de fines de la década de 1960 y principios de 1970. Los portavoces del PSIN nominaron a la identidad ideológica de la agrupación como la "Izquierda Nacional” (IN). La bibliografía académica ha indagado dicha categoría nativa desde múltiples ángulos. Sin pretender trazar un panorama exhaustivo, podemos destacar que la IN ha sido explorada desde la historia de la historiografía, en relación a la inscripción de la producción ensayística de sus referentes en el revisionismo de izquierda (Devoto y Pagano, 2010; Acha, 2009); desde la historia intelectual y cultural, al dar cuenta de la relevancia de la IN en el proceso de reconfiguración de las izquierdas producido durante el periodo peronista y los años sesenta (Ribadero, 2016; Altamirano, 2001); y desde una perspectiva de historia intelectual focalizada en la singularidad teórica de la IN, su relación con el universo conceptual marxista y su ligazón con el nacionalismo y el populismo (Acha, 2013; Georgieff, 2008).

Los primeros estudios sobre los intelectuales y su radicalización en los años '60 se centraron en el recorrido de una franja específica de intelectuales originariamente antiperonistas, dando cuenta de la relevancia que tuvo en su experiencia intelectual la modernización del campo intelectual y cultural producida a partir de 1955 durante el posperonismo, el desencanto ante el desarrollismo, la persistencia de la identidad peronista entre los sectores obreros y populares, la Revolución Cubana y la emergencia de la lucha armada como estrategia revolucionaria, entre otros elementos (Terán, 2013; Sigal, 1991). ${ }^{1}$ En dichas investigaciones se tendió a explicar la radicalización de dichos intelectuales y, más ampliamente, de la juventud universitaria, a partir de la clausura del campo científico y académico impuesto por la autodenominada "Revolución Argentina" de junio de 1966. De este modo, la dictadura de Onganía bloqueó el espacio social en el que los intelectuales podían legitimar sus prácticas profesionales específicas y proseguir con sus programas de actualización cultural e intelectual, estimulando su acercamiento a militancias políticas de corte revolucionario.

\footnotetext{
${ }^{1}$ La convergencia de importantes núcleos intelectuales en el espectro antiperonista, sustentada en motivos diversos como el estilo que el peronismo había introducido en la política argentina o aspectos de su política educativa de corte retrógrado y autoritario, no tardó en resquebrajarse durante el gobierno de la autodenominada "Revolución Libertadora", una vez que la vertiente radicalizada del antiperonismo tomó el control del gobierno bajo el liderazgo del General Pedro Eugenio Aramburu en noviembre de 1955 (Spinelli, 2005; Galván, 2013).
} 
No obstante, se ha señalado que diversos núcleos intelectuales y políticos afines al peronismo, de fuerte gravitación durante las décadas del sesenta y setenta, realizaron un recorrido diferente (Caruso, 2018, pp. 8-17; Roland, 2016, pp. 8-10), donde la especialización en un campo académico no pareció medrar en sus prácticas y perspectivas. Este es el caso de los intelectuales con vocación política que formaron parte de la IN. En esta vertiente político-intelectual la adhesión a la idea de un "cambio de estructuras" por la vía antiimperialista, ampliamente difundida durante los tumultuosos "años sesenta", tomó forma con anterioridad a la "Revolución Libertadora". De este modo, surgen interrogantes acerca de cómo impactó la "Revolución Argentina" en el PSIN, evidentemente de un modo distinto al de la "nueva izquierda intelectual", cuál fue la lectura de la organización respecto de la nueva situación política impuesta por el "Onganiato”, y cómo esa lectura, volcada en sus posicionamientos públicos, brindó un marco de sentido a sus prácticas militantes, en particular en relación al Cordobazo.

Los aportes referidos y nuestra propia investigación permitirán aproximarnos a la identidad ideológica de la IN, para, sobre esa base, focalizarnos en aspectos escasamente atendidos por la bibliografía especializada: la vida organizativa de la corriente, sus posicionamientos partidarios y sus vinculaciones con otras fuerzas políticas y espacios sociales. A su vez, el análisis de la identidad ideológica de la IN permitirá comprender el marco de sentido sobre el que se desenvolvieron las prácticas de los militantes del PSIN, fundamentalmente los insertos en el ámbito universitario. Las dimensiones señaladas serán abordadas desde una escala subnacional, ya que reconstruiremos la conformación del PSIN en la provincia de Córdoba, su despliegue organizativo durante los años sesenta, su inserción en el movimiento estudiantil y su vinculación con el movimiento obrero, en torno al período comprendido entre 1962 (año de conformación del PSIN a nivel nacional) y mediados de 1969 (coyuntura en la que las jornadas de protesta de mayo de 1969, popularmente conocidas como "el Cordobazo", se instalaron en la agenda pública de la Argentina). A su vez, como veremos, para comprender el itinerario de este actor provincial será necesario vincular la dinámica local con la nacional, y con lo acontecido en otras provincias donde el partido tuvo presencia. En tal sentido, prestaremos particular atención a la línea política del partido ante la autodenominada "Revolución Argentina" de junio de 1966, enunciada desde la dirección nacional del PSIN, y a la inserción de la organización en el movimiento estudiantil de otras provincias.

Como veremos, el PSIN de Córdoba, desde su conformación en noviembre de 1963, logró cierta acumulación organizativa que le permitió gravitar en el Cordobazo, fundamentalmente a partir de su inserción en el movimiento estudiantil universitario y su vinculación con determinados dirigentes sindicales. Sostenemos que la reconstrucción del itinerario específico del PSIN permite ampliar los conocimientos existentes en torno al Cordobazo, ya que dicho acontecimiento ha sido indagado, en mayor medida, como una protesta de masas (Balvé y Balvé, 1989), basada en la alianza entre obreros y estudiantes y/o como el inicio de un ciclo de radicalización de las luchas sociales, cuyos emer- 
gentes fueron el sindicalismo clasista y la lucha armada adoptada por determinadas organizaciones de la nueva izquierda. Sin embargo, poco se conoce acerca de la participación de organizaciones políticas en la protesta de mayo. En relación a ello, el PSIN, cuya línea política rechazaba frontalmente la estrategia guerrillera, resulta de particular interés, en tanto la organización pudo tener una participación activa en el Cordobazo por contar de un activo militante formado desde un recorrido previo. En tal sentido, creemos que la historia de partido contribuye a comprender el Cordobazo como el resultado de un largo ciclo de activismo popular, sindical, estudiantil y político-partidario.

\section{Una aproximación a la identidad ideológica de la Izquierda Nacional}

Diversos debates atravesaron el campo de las izquierdas en los años sesenta. La denominada Izquierda Nacional (IN) otorgó centralidad a la interpretación del peronismo, relegando a un lugar secundario otras cuestiones como el desarrollismo, la Revolución Cubana, la lucha armada y el carácter de la URSS y de China (Roland, 2016, p. 15). ${ }^{2}$ Desde dicha clave, la IN procuró diferenciarse tanto de los partidos tradicionales de izquierda -el Partido Socialista (PS) y el Partido Comunista (PC)-, a los que peyorativamente calificó de "cipayos", como de las nuevas formaciones de izquierda intelectual y política (Spilimbergo, 1960).

Sin embargo, las coordenadas fundamentales de la interpretación del "hecho peronista" propuesta por la IN no fueron elaboradas durante el ciclo abierto por la "Revolución Libertadora", sino mucho antes, en los orígenes del movimiento liderado por Perón (Galasso, 2007a, pp. 140-162). Así lo muestran dos publicaciones de filiación trotskista de la década del cuarenta, el periódico Frente Obrero (segunda época) y la revista Octubre. En aquel entonces, los análisis de coyuntura publicados en Frente Obrero, primero, y en Octubre, después, definieron al peronismo como un momento progresivo de la "revolución nacional" de proyección latinoamericana que, a su criterio, requería la Argentina. ${ }^{3}$ En esta mirada, el peronismo impulsó la referida revolución nacional, pero bajo una "jefatura bonapartista nacional-burguesa" y ello abría el camino para una izquierda que lo apoyara críticamente y enfrentara a sus adversarios, la oligarquía y el imperialismo, articulados en un mismo bloque de poder.

\footnotetext{
2 Véase la respuesta de Jorge Abelardo Ramos al cuestionario gestionado por Carlos Strasser (1959, pp. 183212) a los referentes de la nueva izquierda en el posperonismo. Sobre la gravitación del peronismo en la cultura de las distintas vertientes de izquierda, véase: Altamirano (2013).

${ }^{3}$ Formaron parte de Frente Obrero Aurelio Narvaja, Enrique Rivera, Carlos Etkin, Adolfo Perelman y Hugo Sylvester; y de Octubre Jorge Abelardo Ramos y Mauricio Moisés Prelooker. El autor agradece el comentario realizado vía email por el historiador Norberto Galasso a la ponencia homónima a este artículo, presentada en las jornadas A cincuenta años del Cordobazo: repensando el ciclo de protestas obreras, rebeliones populares e insurrecciones urbanas, organizados por la Facultad de Filosofía y Humanidades de la UNC, en mayo del 2019. El comentarista observó que Frente Obrero caracterizó al peronismo como un emergente positivo de la lucha de clases en sus orígenes, a pocos días del 17 de octubre de 1945. En cambio, Octubre adoptó una caracterización similar con posterioridad, en su número 2, publicado en noviembre de 1946.
} 
Tanto durante los dos mandatos de Perón, como luego de su derrocamiento, estos militantes desplegaron una intensa labor político-cultural, observable en la publicación de periódicos, revistas y libros y la gestación de editoriales como Indoamérica, Amerindia y Coyoacán (Ribadero, 2016). Hacia comienzos de los sesenta, esta vertiente de izquierda logró mayor cohesión interna bajo el liderazgo de Jorge Abelardo Ramos y fundó, en julio de 1962, el Partido Socialista de la Izquierda Nacional (PSIN); una organización de matriz leninista que pretendía representar a la clase trabajadora desde el resguardo, en su seno, del saber marxista revolucionario. ${ }^{4}$ En su autopercepción del proceso referido, Ramos, el dirigente de la IN de mayor gravitación pública en los años sesenta y setenta, señaló que durante la década del cuarenta y del cincuenta la corriente priorizó el trabajo intelectual por sobre el estrictamente político, ya que la fuerte identificación de los trabajadores con el peronismo llevaba al fracaso toda tentativa de organizar un "partido independiente de la clase trabajadora" (Ramos, 1964, pp. 138-140). ${ }^{5}$ Sin embargo, en su mirada, ese escenario se habría modificado durante los años sesenta, ya que tanto por la incapacidad del peronismo para conservar el poder político como por la "traición de Frondizi", los trabajadores y las clases medias mostraban una nueva percepción de la realidad del país, mucho más auspiciosa para el proyecto político de la IN. ${ }^{6}$

Para la IN el sujeto revolucionario en la Argentina de los años sesenta debía constituirse desde una articulación -a la que denominó "alianza plebeya" - entre la clase media y el proletariado urbano (Spilimbergo, 2010 [1964], pp. 50-51). ${ }^{7}$ Desde esta definición, la IN no excluía la convergencia con fracciones de la "burguesía nacional" en tanto tendieran hacia un proyecto de industrialización autónoma del país. No obstante, consideraba que estos sectores capitularían en el proceso de revolución nacional, por lo que resultaba

\footnotetext{
${ }^{4}$ Comité Ejecutivo del Partido Socialista de la Izquierda Nacional (PSIN) (julio de 1962). La Izquierda Nacional ya tiene su partido. URL: http://www.abelardoramos.com.ar/la-izquierda-nacional-ya-tiene-su-partido/. (Descarga: 28/11/19).

${ }^{5}$ En efecto, durante las presidencias de Perón, las dos principales intervenciones públicas de Ramos, los ensayos América Latina, un país (1949) y Crisis y resurrección de la literatura argentina (1954), procuraron disputar el monopolio de la legitimidad cultural a la intelectualidad ubicada en la oposición al peronismo (Tortorella, 2012). De este modo, el autor, un agente periférico inserto en la intersección entre el campo intelectual y el político, construyó una legitimidad específica, sustentada en una representación de la actividad intelectual en tanto reflexión para la subversión política del orden social.

${ }^{6}$ A seis meses de la asunción de Arturo Frondizi, los referentes de la IN publicaron siete números de la revista Política (Ribadero, 2015). Por este medio, enunciaron su posicionamiento ante el frondizismo y polemizaron con los intelectuales de izquierda que lo apoyaron y/o se sumaron a sus filas, en particular los agrupados en la revista Contorno. Si bien el núcleo liderado por Ramos y Spilimbergo no depositó expectativas en torno al nuevo presidente, sostuvo, fundamentalmente a partir de la intervención de Enrique Rivera, que la experiencia desarrollista fue un momento progresivo de "nacionalización de las clases medias", ya que vinculó a sus nuevos segmentos - profesionales, intelectuales, pequeños industriales, técnicos y comerciantes-, con la problemática económica e industrial y con el desafío de resolver la crisis política argentina desde el armado de un "frente nacional".

${ }^{7}$ El ensayo citado es una síntesis de los debates sostenidos en el tercer congreso del PSIN, realizado en Villa Allende, Córdoba, en 1964. Su primera publicación llevó el título de Tesis Políticas del Partido Socialista de la Izquierda Nacional y fue presentado como un documento partidario, pese a que su elaboración corrió por cuenta de Jorge Enea Spilimbergo, uno de los principales referentes de la IN.
} 
necesario delimitarse de ellos, estén representados por el peronismo o por el desarrollismo. Es importante destacar que la IN no consideraba al peronismo una expresión directa y transparente de la burguesía nacional argentina. De allí, el uso de los conceptos "movimiento nacional" y "bonapartismo", tomados, fundamentalmente, de la perspectiva leninista sobre el "mundo colonial y semicolonial", irradiada a los cuatro primeros congresos de la Internacional Comunista, y de la caracterización del gobierno mejicano de Lázaro Cárdenas efectuada por Trotsky en su exilio en México. En esta tesitura, ante las agresiones de los países imperialistas -geopolítica correspondiente a la fase estructural de concentración del capital en dichos países-, los "movimientos nacionales" expresaban una respuesta que bregaba, en mayor o menor medida, por la independencia nacional y la reforma agraria. Desde esta coordenada, se interpretaba a los "populismos latinoamericanos" como "movimientos nacionales" o "frentes nacionales", una fuerza policlasista de orientación industrialista y antiimperialista conformada por la clase trabajadora, las clases medias, campesinos y fracciones de la burguesía nacional y las Fuerzas Armadas (Acha, 2013, p. 61).

A su vez, el peronismo encarnaba una dirección "bonapartista" del movimiento nacional, lo que implicaba que esta fuerza realizaba los intereses de una clase social -la burguesía industrial- desplazándola del poder político. Por tanto, el peronismo, en tanto proyecto de acumulación capitalista de base nacional e industrial, era progresivo, pero irremediablemente trunco, en tanto carecía del soporte real de la clase social beneficiada. En esta perspectiva, solo el relevo de la clase trabajadora organizada en un partido independiente garantizaba la realización de las "tareas nacionales" y abría el camino de las "tareas socialistas", en una formulación tomada de la teoría de la revolución permanente de Trotsky (Laclau, 2013). En el curso ascendente de la revolución nacional, la IN debía realizar una tarea socialista central, la expropiación estatal de los grandes latifundistas de la Pampa Húmeda -su "nacionalización"- afectando así el derecho burgués a la propiedad privada. A partir de esta medida, se podría emplear la renta agraria diferencial de la Pampa Húmeda en la industrialización planificada de la economía. ${ }^{8}$ Ahora bien, una transformación de esta naturaleza no iba a lograr legitimidad en la sociedad sin una adecuada "superestructura ideológica". ${ }^{9}$ Ello justificaba la necesidad de formar una perspectiva integral sobre la realidad del país y, más extensivamente, de América Latina. De allí, la importancia que la IN otorgó a la política intelectual y cultural, como consignamos anteriormente. ${ }^{10}$

\footnotetext{
${ }^{8}$ A dicha medida debía sumarse la "expropiación de la burguesía comercial, de los frigoríficos y de otras inversiones extranjeras que ahogan al país". Comité Ejecutivo del PSIN (julio de 1962), op. cit., p. 4.

${ }_{9}$ Ramos, J. A. (octubre de 1963). La ideología socialista en la revolución nacional. Izquierda Nacional, 4, pp. 810. La revista citada era el órgano teórico del PSIN.

${ }^{10}$ Dicha producción político-cultural tuvo un importante componente historiográfico, orientado a formar una conciencia histórica de la realidad nacional y latinoamericana. Compartimos la apreciación propuesta por Acha (2009, pp. 203-214) y ampliada por Caruso (2018, pp. 148-198), relativa a la especificidad de la historiografía de la IN, que debe ser diferenciada de otras vertientes del revisionismo histórico de la década del sesenta, en particular de la historiografía de la izquierda peronista. Para una definición del carácter diferencial de la historiografía de la IN, a la que sus representantes denominaron "revisionismo socialista",
} 
Para los portavoces de la IN, el nacionalismo popular latinoamericano, al que diferenciaron de las versiones conservadoras, católicas y fascistoides del nacionalismo de la época, realizó un aporte significativo en la formación de una conciencia nacional e histórica sobre Latinoamérica. Desde esa óptica, la IN bregó por una imbricación entre el nacionalismo popular y el socialismo marxista (Georgieff, 2008; Acha y Eidelman, 2000), ya que ello iba a dotar al bloque de fuerzas nacional-populares de una ideología adecuada (Spilimbergo, 1958, p. 80). En tal sentido, la historiografía de la IN destacó la importancia de la Reforma Universitaria de 1918, fundamentalmente en sus postulados originarios y en su proyección latinoamericana, en particular su irradiación en el aprismo peruano (Ramos, 1970, pp. 258-272). Desde esta interpretación, se reivindicaba la modernización de los planes de estudio de las Universidades, su apertura a la problemática nacional, la democratización del gobierno universitario en tanto inserción de la pequeña burguesía en la vida pública, la independencia y unidad continental y la vinculación entre el movimiento estudiantil y la clase trabajadora. De este modo, el movimiento estudiantil originado en la Universidad Nacional de Córdoba (UNC) representaría un contradictorio "segundo Ayacucho del espíritu", que obró como vector ideológico de una perspectiva revolucionaria que debía encontrar su resolución en la lucha política.

Sin embargo, para esta perspectiva, el radicalismo yrigoyenista, en tanto primer movimiento nacional moderno de base social pequeño burguesa urbana y rural (Roland, 2018), se habría revelado incapaz de dar cauce efectivo al impulso reformista y este, ante la ausencia de una ideología socialista "nacional", terminó cooptado por la izquierda tradicional en la década del treinta. La desviación del sentido originario del reformismo derivó en su inserción en el bloque de fuerzas oligárquico-imperialista. Desde esa clave era interpretada la participación de la Federación Universitaria Argentina en las movilizaciones opositoras al presidente Irigoyen durante su segunda presidencia y el apoyo del estudiantado universitario a la Unión Democrática y a la "Revolución Libertadora". Como puede notarse, dicho desplazamiento político-ideológico del reformismo atentaba contra la clave de la revolución nacional: la "alianza plebeya".

Por lo tanto, la militancia de la IN en el movimiento estudiantil de los años sesenta se propuso recuperar la orientación nacional y popular de la gesta reformista y, desde ese marco de sentido, impulsar una articulación entre el estudiantado y la clase trabajadora. ${ }^{11}$ De este modo, la alianza plebeya impulsada por el PSIN reivindicó aspectos progresivos de la experiencia obrera en el peronismo y la tradición reformista leída en clave nacional y popular, y buscó vincularlos a una perspectiva socialista en aras de llevar a

véase el ensayo del intelectual cordobés Alfredo Terzaga (1974). Dicho autor, pese a ser un confidente y colaborador de Ramos, no formó parte de las organizaciones de la IN de manera orgánica; no obstante, su obra presenta una clara filiación en esta corriente y las diversas iniciativas que desarrolló en Córdoba durante los años sesenta contribuyeron a difundir la perspectiva de la IN y la propuesta del PSIN.

${ }^{11}$ La Universidad: política revolucionaria o fraseología "unitaria" (febrero de 1966). Izquierda Nacional (segunda época), 2, pp. 14-17. 
término la revolución nacional que el peronismo no había podido consumar. Es pertinente observar que el proyecto político de la IN tuvo lugar en un marco de radicalización ideológica de la sociedad, donde cobró fuerza la idea de un "cambio de estructuras", tematizada, en muchos casos, desde la consigna de "liberación nacional". Esto implicó una extendida representación del sometimiento de la Argentina y de sus mayorías populares al imperialismo occidental (Brennan y Gordillo, 2008, pp. 62-79; Gordillo, 2007). Veamos ahora el posicionamiento del PSIN ante la dictadura de Onganía y el despliegue organizativo del partido durante los años sesenta.

\section{El PSIN ante la "Revolución Argentina", su línea política y su despliegue organizativo}

La autodenominada "Revolución Argentina", comandada por el General Juan Carlos Onganía, implicó, desde el punto de vista del PSIN, una reconfiguración del mapa sociopolítico. En primer término, el ciclo político abierto en septiembre de 1955 había dotado al bloque oligárquico-imperialista de una base social de masas formada por la clase media antiperonista. En tal sentido, resultaba significativo que la dictadura que había derrocado a Perón había satisfecho las demandas del movimiento estudiantil antiperonista en relación a la política educativa y universitaria:

Con el fin de esclarecer por la vía analógica y con un sentido provisional la política de Onganía, diremos que la revolución libertadora intervino la CGT, inhabilitó gremialmente a 150.000 delegados de fábrica y envió a Ushuaia a los peronistas. En cuanto a la pequeña burguesía, su actitud fue radicalmente diferente: después de expulsar a los profesores peronistas de sus cátedras, restableció el gobierno tripartito, la libertad de cátedra para todos salvo para los peronistas y afirmó la autonomía universitaria. La oligarquía liberal y la pequeña burguesía de izquierda (Dell Oro Maini y José Luis Romero) sellaron una sagrada alianza durante diez años. ${ }^{12}$

De este modo, la intervención de las Universidades públicas decretada por la ley 16.912 de fines de julio de 1966, que acababa con la autonomía universitaria, la ampliación de la restricción política (que ya no cubría solo al peronismo sino al conjunto de los partidos políticos), y el estilo retrógrado y conservador que sectores católicos le imprimieron a la nueva dictadura, empujaban a la clase media ligada al mundo universitario hacia la oposición. De este modo, el PSIN anticipó que el régimen en gestación iba a politizar a un amplio espectro de grupos sociales y políticos:

Debemos decir que si el gobierno proscribe el ejercicio de la política a todo el país, todos los problemas políticos de los argentinos refluirán sobre el Ejército. Esta institución se convertirá, quiéralo o no el gobierno, en una caldera política sometida a una alta presión. La sociedad, como la naturaleza, 'aborrece el vacío'. El apoliticismo militar, que tantas veces hemos visto en los últimos treinta años, se convertirá, por

\footnotetext{
${ }^{12}$ La Argentina: pregunta y respuesta (octubre de 1966). Izquierda Nacional (segunda época), 3, p. 4.
} 
la fuerza de las cosas en una acción política frenética de incalculables consecuencias. $^{13}$

Ahora bien, en los comienzos del nuevo régimen el PSIN adoptó una posición de espera hasta que se definiera la pugna de tendencias internas que, a criterio del partido, atravesaba al nuevo gobierno. En consonancia con las declaraciones vertidas desde España por Perón, el PSIN señaló que la orientación del gobierno era indeterminada, ya que en su interior se encontraban tanto representantes del bloque oligárquico-imperialista como el ministro de economía Jorge Salimei, vinculado a grupos económicos de capital nacional, y se había establecido un diálogo con el sindicalismo peronista a partir de la restitución de personerías gremiales y la aprobación de nuevos convenios colectivos. $^{14}$

Sin embargo, al poco tiempo el PSIN difundió su caracterización definitiva del nuevo régimen, al que denominó "Segunda Revolución Libertadora". Para esta nueva definición fue clave el lanzamiento del plan de "modernización en tres tiempos" y el nombramiento de Krieger Vasena como ministro de economía a fines de 1966:

\begin{abstract}
"Modernizar" significa, en síntesis, depurar al Estado de toda la superestructura jurídica erigida en la época de Perón y adecuarla a la realidad económica actual. De acuerdo a esta utopía reaccionaria, la industria caerá en manos de las grandes empresas extranjeras (proceso que ya ha comenzado). El Estado debe reducir su personal y dirigirlo 'hacia la actividad privada', lo que resultará imposible por la retracción inminente. Por el contrario, la clase media así desplazada caerá en una masa de desocupados, análoga a la de los tiempos de la década infame. El ferrocarril debe ser desmantelado para brindar un campo de competencia al automotor. La misma industria automotriz quedaría en poder de las empresas mundiales, como la Ford y la General Motors. Kaiser, en esa política sería adquirida por aquella y probablemente cerradas sus fábricas. Monopolio industrial extranjero, regido por la 'eficiencia', estructura agraria inmodificable e improductiva, ejército de desocupados para doblegar los convenios colectivos, bajas tarifas de avalúos para barrer aquellas industrias nacionales incapaces de enfrentar la competencia extranjera, tal es el patrón de la política de 'modernización'. Simultáneamente, y como parte de la política oligárquica, el proteccionismo industrial es desacreditado por los voceros del gobierno, y el librecambismo erigido como una panacea económica. El Fondo Monetario Internacional interviene descaradamente en la elaboración de esta masacre de los intereses nacionales. Así lo anuncia Rusk en Washington, como otrora se hacía en Londres. La devaluación del peso argentino, dictada afuera, refluye sobre el Uruguay, que se ve obligado a devaluar el peso oro, como secuela. Todo el país se reventará contra esta política de suicidio nacional. ${ }^{15}$
\end{abstract}

\footnotetext{
${ }^{13}$ Ibídem, p. 3.

${ }^{14}$ La posición de espera del PSIN derivó en una fuerte crítica del intelectual Ismael Viñas, dirigente del Movimiento de Liberación Nacional (MLN), publicada en el semanario Marcha y replicada por Ramos en la revista Izquierda Nacional. Ramos, J. A. (octubre de 1966). El Ejército Argentino y la teoría de Pavlov. Izquierda Nacional (segunda época), 3, pp. 6-9.

${ }^{15}$ La Segunda Revolución Libertadora (marzo de 1967). Izquierda Nacional (segunda época), 4, pp. 8-9.
} 
De este modo, la dictadura que otorgó la suma del poder público a Onganía tendía a acercar, en su contra, a la clase trabajadora con la clase media. En este marco, el desafío político residía en fortalecer y dinamizar dicha vinculación, construyendo una dirección política de orientación socialista de alcance nacional. ${ }^{16}$ Para ello, el PSIN prosiguió con el despliegue organizativo que había comenzado, como vimos, a mediados de 1962 con la fundación del partido. Ello derivó en una progresiva inserción en el movimiento estudiantil de diversas universidades nacionales.

En el caso de la Universidad de Buenos Aires (UBA) se destacó un temprano avance, ya que la agrupación Frente de Acción Universitaria (FAU) del Centro de Estudiantes de la Facultad de Filosofía y Letras (CEFyL) de la UBA, se incorporó al PSIN a fines de 1963 (Regali, 2012, pp. 313-320; Galasso, 2008b, pp. 17-25). Dicha organización fue liderada por el joven Ernesto Laclau, quien anteriormente había sido presidente del CEFyL y representante reformista en el Consejo Superior de la UBA, y era integrada por un importante núcleo de activistas, entre los que destacaron Félix Gustavo Schuster, María Inés Ratti, Adriana Puiggrós, Ana Lía Payró y Blas Alberti. A partir de dicha incorporación, el PSIN impulsó un espacio universitario denominado Juventud Universitaria de Izquierda Nacional (JUIN), que condujo al Movimiento Universitario Reformista (MUR), la agrupación mayoritaria del CEFyL. A partir de ello, la militancia universitaria del PSIN protagonizó la ocupación del rectorado de la UBA en mayo de 1964, en apoyo a la segunda etapa del plan de lucha de la CGT. ${ }^{17}$ Sin embargo, el núcleo incorporado sufrió rápidas deserciones y la inserción del PSIN en el estudiantado de Buenos Aires no logró consolidarse, situación que comenzó a revertirse hacia comienzos de la década del setenta. ${ }^{18}$

En Córdoba, como veremos, la inserción en el movimiento estudiantil acompañó a la construcción del partido. La provincia mediterránea ya contaba con cierta irradiación de las tesis de la IN y una red de sociabilidad promisoria para la propuesta del PSIN (Regali, 2012, pp. 256-266). En tal sentido, fue relevante el desempeño de Alfredo Terzaga, un intelectual oriundo de Río Cuarto, radicado en la capital de la provincia a mediados de

\footnotetext{
${ }^{16}$ Si bien el PSIN seguía con atención los posicionamientos políticos del movimiento obrero y buscaba converger con sus expresiones más combativas, dada su matriz leninista no esperaba que la radicalización del sindicalismo resolviera la situación del país en un sentido revolucionario; más bien, tal tendencia era un fenómeno coadyuvante a dicho propósito, pero no el factor determinante. Spilimbergo, J. E. (15 de mayo 1966). Reformismo sindical y partido revolucionario. Lucha Obrera, 28, p. 3.

${ }^{17}$ En poco tiempo, Laclau, Payró, Ratti y Alberti se incorporaron a la Mesa Ejecutiva del PSIN y el primero de ellos pasó a dirigir la revista teórica Izquierda Nacional (primera época) y el periódico partidario Lucha Obrera, trabando una relación muy estrecha con Ramos.

${ }^{18}$ En base a la observación de las autoridades del nuevo partido y la incorporación del "grupo Laclau", tal como se denominó a FAU en la jerga interna del PSIN, Norberto Galasso (2008b, pp. 17-25) ha destacado el predominio de la clase media universitaria en los orígenes del PSIN. En tal sentido, sobre un total de diecisiete miembros del primer comité ejecutivo nacional, solo tres eran de extracción obrera: Manuel Fernando Carpio (Secretario General), Alberto Belloni (vocal) y Ángel Perelman (vocal). Como veremos, el PSIN en la provincia de Córdoba adoptó una composición social similar. El autor citado destaca que se incorporan al nuevo partido núcleo zonales del Chaco (dirigido por Carlos Díaz y conformado por alrededor de cuarenta militantes), de Bahía Blanca (dirigido por Rubén Bortnik) y de Necochea (dirigido por Oscar Aramburu).
} 
la década del treinta (Ferrero, 2010). En la ciudad de Córdoba, Terzaga se vinculó al grupo trotskista conformado por Esteban Rey, Aurelio Garro y el boliviano Gustavo Navarro, identificándose con esta vertiente del marxismo. Por este medio conoció a Abelardo Ramos entre 1939/40, pasando a ser su principal contacto en la provincia. En sus notas del diario Orientación, Terzaga suscribió a la perspectiva ideológica de la IN y cubrió iniciativas de Ramos como la publicación de la primera edición del libro Revolución y Contrarrevolución en la Argentina, en agosto de 1957 (Ribadero, 2016, p. 253). ${ }^{19}$ A su vez, el intelectual riocuartense impulsó la revista Discusión, publicada entre junio y octubre de 1956; y organizó el Ateneo CANLA (Centro de Acción Nacional Latinoamericana) orientado al debate político e ideológico, activo entre 1957 y 1958. Por estas vías el núcleo porteño de la IN comenzó a trabar vínculos con militantes de izquierda de Córdoba y difundió la bibliografía de sus editoriales.

Posiblemente estas iniciativas comenzaron a tener acogida en la provincia debido al descontento de militantes de izquierda con los partidos tradicionales y su posicionamiento ante el peronismo. En tal sentido, tras la reelección de Perón en noviembre de 1951, se constituyó en Buenos Aires un pequeño grupo de disidentes del PS, agrupados en torno a una publicación, Acción Socialista (AS), bajo el liderazgo de Dardo Cúneo (Herrera, 2011, p. 9). En Córdoba, se sumaron a la disidencia socialista Héctor Devalle y los abogados Lucio Garzón Maceda y Silvio Mondazzi, entre otros militantes. ${ }^{20}$ Este último era miembro de la Agrupación de Estudiantes Reformistas (ADER) con gravitación en el Centro de Estudiantes de Derecho (CED) de la Facultad de Derecho en la Universidad Nacional de Córdoba (UNC) y, posteriormente, fue el secretario general del PSINCórdoba.

Luego de la caída de Perón, en dicha casa de estudio se consolidó la agrupación Unión Reformista Universitaria (URU), desplazando a la referida ADER. A comienzos de los sesenta, URU se vio atravesado por la reconfiguración ideológica en curso y la creciente tendencia de acercamiento entre el movimiento estudiantil y la clase trabajadora, mayoritariamente peronista (Ferrero, 2009, pp. 124-135). ${ }^{21}$ Desde esta agrupación se posicionó

\footnotetext{
${ }^{19}$ Las notas de Terzaga publicadas en Orientación fueron compiladas en Terzaga (2010), junto a capítulos de su ensayo San Martín y la Política Exterior argentina de 1950. Orientación era un diario cercano al peronismo, dirigido por Terzaga entre septiembre de 1954 y la "Revolución Libertadora". Luego del golpe de Estado, el periódico interrumpió sus actividades, pero volvió a editarse a principios de 1956, al ser adquirido por Antonio Sobral, pedagogo y dirigente frondizista de Villa María, quien re-incorporó a Terzaga como redactor. ${ }^{20}$ Sobre este núcleo se incorporaron, en una táctica "entrista", dos militantes anteriormente vinculados a la revista Octubre de Ramos, Saúl Hecker y Kauffman (Regali, 2012, p. 257). Del segundo el autor se desconoce el nombre de pila.

${ }^{21}$ Entrevista a Víctor Hugo Saiz, Córdoba, 12/03/2019. El entrevistado nació en Córdoba, en una familia cuyo padre, Eleodoro Saiz, fue un inmigrante anarquista vasco de una extendida militancia sindical en la Argentina. Durante el posperonismo, Saiz (padre) llegó a ocupar la secretaría gremial del Sindicato de Viajantes de Córdoba y la Secretaría General de la Federación Única de Viajantes de la Argentina (FUVA). Desde su núcleo familiar, Víctor Hugo se identificó con las ideas anarco-sindicalistas, por lo que transitó la "Revolución Libertadora" desde una identidad antiperonista. A comienzos del sesenta comenzó sus estudios de abogacía y participó del CED de la UNC. En ese marco asistió a una conferencia dictada por Ramos. Luego trabó vínculo con Roberto Ferrero y Silvio Modazzi y se incorporó al PSIN con motivo de su tercer congreso
} 
Abraham Kosak, estudiante procedente de Chaco, como un importante líder del movimiento estudiantil. ${ }^{22}$ De URU formó parte el estudiante Roberto Reyna, oriundo de Villa María. Hacia fines de 1962, URU organizó un ciclo de conferencias y ello motivó que Reyna se contacte con Ramos en Buenos Aires (Regali, 2012, pp. 305-312). A partir de este diálogo, Reyna decidió incorporarse al PSIN y sumó a dicha apuesta a otros dos miembros de URU, el riojano Mario Zenón de la Vega y el salteño Roberto Díaz. De este modo, estos militantes constituyeron la JUIN en la UNC a mediados de 1963, en similar tesitura a lo acontecido en la UBA. ${ }^{23}$ Este incipiente núcleo estudiantil del PSIN pasó a dirigir un desprendimiento de URU, la Unión Reformista Universitaria Principista (URUP), conformado en agosto de 1961; paradójicamente un sector originariamente contrario al acercamiento de URU al ideario de liberación nacional y unidad obrero-estudiantil. A partir de ello, el PSIN logró cierta inserción en la Facultad de Derecho de la UNC, pero a diferencia de lo ocurrido en la UBA, la JUIN de Córdoba no logró constituirse como un actor dominante en la primera facultad en la que gravitó. Sin embargo, el PSIN sostuvo su presencia en la Facultad de Derecho y luego pudo ampliar su peso relativo. A su vez, esta primera inserción en el movimiento estudiantil dio lugar al primer comité zonal de la provincia, conformado en noviembre de 1963 por Roberto Reyna, en calidad de Secretario General, y Roberto Ferrero, Mario Zenón de la Vega, Roberto Díaz y Cristina Garro como delegados provinciales ante el Comité Nacional.

A comienzos de la dictadura de Onganía, URUP ya había consolidado su inserción en la Facultad de Derecho, incorporando nuevos militantes estudiantiles como Gustavo

nacional realizado en Villa Allende, Córdoba, en 1964. Desde su incorporación participó tanto de la militancia estudiantil como sindical, ya que hacia mediados de los sesenta ingresó como empleado al Poder Judicial provincial y se sumó al Sindicato de Empleados Judiciales. Por esa vía y por la representación que tenía su padre en la CGT-Regional Córdoba, Saiz tomó el vínculo de la organización con el movimiento obrero. En 1967 fue designado secretario general del PSIN-Córdoba, la máxima responsabilidad partidaria, acompañado por Modazzi como secretario político, quien había precedido a Saiz en su nueva función. Ocupó este cargo hasta 1970, momento en el que migró hacia Bolivia, para colaborar en la construcción de la IN en Bolivia junto a Adolfo Perelman, uno de los fundadores de la Unión Obrera Metalúrgica (UOM) en abril de 1943 y del PSIN en julio de 1962, y Andrés Solís Rada, intelectual boliviano y dirigente del Sindicato de Periodistas.

${ }^{22}$ Roberto Ferrero (2009, pp. 124-135) observa que Kosak recibió una doble influencia ideológica. Por una parte, por el grupo de intelectuales vinculados a la revista Pasado y Presente, cuyo referente provincial era José María Aricó. Por otra, por la IN. Ello fue corroborado por Víctor Hugo Saiz y se evidencia en la trayectoria posterior de Kosak, ya que, en 1971, luego de su intenso recorrido como dirigente estudiantil, se incorporó al Frente de Izquierda Popular (FIP) - una estructura frentista creada por el PSIN y orientada por la perspectiva ideológica de la IN-, llegando a ser su apoderado legal.

${ }^{23}$ Entrevista a Roberto Ferrero vía email, Córdoba, 27/03/2019. El entrevistado nació en San Francisco, provincia de Córdoba. En 1958 se trasladó a la capital, para estudiar Derecho en la UNC. Su primera experiencia política fue en la Unión Cívica Radical Intransigente (UCRI), entre 1956 y 1959, y luego prosiguió su militancia en el Partido Obrero Revolucionario Trotskista (POR-T) liderado por J. Posadas. Hacia 1963, mientras vivía en una pensión familiar ubicada en Obispo Salguero 169 y desarrollaba sus estudios en Derecho en la UNC, se incorporó a URU. A instancia del mencionado Reyna, Ferrero trabó un vínculo con Terzaga y, por esta vía, tomó forma su acercamiento a la IN. A partir de allí, fue uno de los referentes del PSIN en la provincia hasta 1968, momento en el que se apartó de la organización. El autor agradece el comentario del entrevistado a la ponencia homónima a este artículo, realizado por email. A partir de este aporte se pudo rectificar información relativa a la conformación del PSIN-Córdoba. 
Gallardo, Nora Peretti, Estela Uriondo y Gustavo Terzaga (hijo de Alfredo) entre otros (Ferrero, 2009, p. 176). A su vez, el brazo estudiantil del PSIN extendió su presencia a las Facultades de Medicina, Odontología, Ciencias Económicas y el Instituto de Matemática, Astronomía y Física (IMAF), de la UNC. En ese marco, la militancia universitaria del PSIN atravesó un debate interno relacionado a la política universitaria y la estrategia de la organización en este ámbito. ${ }^{24}$ En ese sentido, el partido evaluó que estructuras como la JUIN no eran un instrumento adecuado para la inserción en el movimiento estudiantil, ya que un espacio nominado desde una identificación político-ideológica explícita no permitía ganar representatividad entre las bases estudiantiles. De este modo, se optó por impulsar agrupaciones de mayor autonomía respecto del PSIN, que alentaran la participación tanto de militantes del partido como de estudiantes regulares. Estos espacios debían focalizarse en las demandas del movimiento estudiantil, sin abandonar la identidad reformista nacional-popular, pero relegando a un lugar secundario debates que no atravesaran directamente al estudiantado. Desde estas coordenadas se organizó la agrupación Acción Reformista Estudiantil Nacional (ARENA), continuadora de URUP, a comienzos de 1968, que extendió su presencia hacia la Facultad de Arquitectura de la UNC (Ferrero, 2008, pp. 189-191). ${ }^{25}$

Sin embargo, ARENA tuvo corta vida, ya que hacia octubre de 1968 se fusionó con el Centro de Estudios y Lucha (CEL) de la Facultad de Medicina, liderado por Pascual Bianconi y Silvia Benítez, dirigentes de destacada participación en las asambleas estudiantiles previas al Cordobazo, conformando la Agrupación Nacional Universitaria (AUN). Desde esta estructura organizativa, el PSIN logró ampliar su rango de gravitación hacia las facultades de Ciencias Químicas, Filosofía y Humanidades y la Universidad Tecnológica Nacional (UTN). ${ }^{26}$ Como puede observarse, el nuevo escenario abierto

\footnotetext{
${ }^{24}$ Entrevista a Eduardo González, Córdoba, 24/03/2019. El entrevistado nació en una familia de clase media de Córdoba capital contraria al peronismo. A los nueve años participó de la movilización "primavera sin Perón", en septiembre de 1955. Una vez derrocado Perón, entró en crisis con la autopostulada identidad democrática de la "Revolución Libertadora". Luego, hizo sus estudios secundarios en el Colegio Manuel Belgrano y, al finalizarlos, comenzó la licenciatura en Física en el IMAF de la UNC, a mediados de los sesenta. Allí, se incorporó al PSIN, desde la militancia universitaria. Desde este espacio participó en la protesta estudiantil iniciada agosto de 1966, en reclamo por la restitución de la autonomía universitaria y el co-gobierno. El autor agradece la generosidad del entrevistado por facilitar el acceso a su colección personal de la revista Izquierda Nacional (segunda época).

${ }^{25}$ Entrevista a Aurelio Argañaraz, Córdoba, 08/03/2019. El entrevistado nació en Córdoba Capital, pero vivió parte de su adolescencia en San Francisco del Chañar, una antigua localidad del norte provincial. A principios de 1965, mientras estudiaba en el Colegio Manuel Belgrano, se incorporó, junto al estudiante secundario Luis Vicens del Colegio Cristo Rey, al PSIN de Córdoba. Ambos estudiantes se ligaron al nuevo partido político a partir de la lectura de Revolución y contrarrevolución... y del periódico partidario Lucha Obrera. El autor agradece la generosidad del entrevistado por facilitar el acceso a su colección personal de Lucha Obrera. El entrevistado también observó que, en el primer tramo de la "Revolución Argentina", se desarrolló la militancia secundaria del PSIN-Córdoba, en los centros de estudiantes de los colegios Deán Funes y Ricardo Rojas.

${ }^{26}$ Hacia 1967 el PSIN también había logrado cierta inserción en la Universidad Nacional del Litoral (UNL), provincia de Santa Fe, en las facultades de Derecho y Ciencias Químicas, donde formaron una agrupación homónima a la de Córdoba: ARENA. A su vez, en la Universidad Nacional de Tucumán (UNT), con la
} 
por la "Revolución Argentina" permitió la inserción y el crecimiento de la militancia estudiantil vinculada al PSIN.

Ahora bien, se ha observado que durante la dictadura de Onganía se produjo una fuerte reconfiguración del movimiento estudiantil universitario, en estrecha relación con la radicalización ideológica y política de la sociedad anteriormente referida (Brennan y Gordillo, 2008, pp. 76-79). Durante el primer tramo de la década del sesenta, el Movimiento Reformista era el actor dominante en el movimiento estudiantil, tanto a nivel nacional como provincial. En esta tendencia gravitaban activistas ligados a la izquierda tradicional, el PC y el PS, y algunos radicales y demócratas cristianos. Por otra parte, durante el período se desarrollaron importantes corrientes de raíz cristiano-católica, en particular el Integralismo que, pese a partir de una posición "apolítica", abrazó progresivamente el ideario de liberación nacional y unidad obrero-estudiantil, lo que llevó a muchos de sus militantes a incorporarse al peronismo. Un hito de la radicalización del Integralismo fue su participación en la lucha estudiantil de agosto de 1966, contraria a la intervención de casi todas las casas de estudio del país dictada por el gobierno de Onganía, una medida enfáticamente rechazada por la militancia universitaria. ${ }^{27}$

En este marco se tendió a configurar una convergencia de las diversas corrientes estudiantiles en oposición a la dictadura, las intervenciones de las universidades nacionales y las medidas restrictivas para el ingreso estudiantil en las mismas, como los cupos de ingreso y los exámenes eliminatorios, a las que el movimiento estudiantil denominó "limitacionismo" y a las que opuso su demanda de "ingreso irrestricto" del estudian-

llegada de Laclau como profesor, se organizó un importante núcleo estudiantil, en vinculación con el claustro docente, que hacia 1967 conformó la Agrupación Universitaria Nacional (AUN) originaria y conquistó la conducción de la Federación Universitaria de Tucumán (FUAT), en alianza con otras agrupaciones. La experiencia tucumana motivó la organización de AUN en Buenos Aires, Entre Ríos, Santiago del Estero y Córdoba. La bandera principal de AUN-Córdoba fue la reconstrucción de los centros de estudiantes de la FUA y de las federaciones regionales, proponiendo la participación democrática de todas las tendencias estudiantiles en su interior, sean reformistas o no, ya que estos órganos eran "instrumentos de lucha" del conjunto del estudiantado (Ferrero, 2009, pp. 221-223). Sin embargo, pese a su expansión, AUN todavía no reflejaba una estrategia universitaria unificada nacionalmente, que abarcara a todos los distritos donde el PSIN tenía presencia. Ello, más bien, tuvo lugar a partir del "Congreso Nacional Constituyente de AUN", realizado en Río Ceballos, provincia de Córdoba, en septiembre de 1969, y de la tarea de centralización que asumió Spilimbergo como secretario universitario del partido. A partir de allí, el PSIN transitó un ciclo de ascendente gravitación en el movimiento estudiantil, que derivó en la conquista de la FUA en su décimo congreso realizado en 1970, a partir de una alianza entre AUN y una vertiente de Franja Morada de orientación socialista, con peso en las universidades de Rosario y La Plata, en oposición a la Franja Morada de orientación radical, el MNR y al Partido Comunista Revolucionario (PCR). El manifiesto de dicho congreso reivindicó la gesta "nacional, popular y latinoamericana" del reformismo de 1918 y la manifestación obrera del 17 de octubre de 1945, adoptando un marco de sentido propio de la IN.

${ }^{27}$ Debe tenerse en cuenta que durante el primer tramo del posperonismo, determinados clivajes enfrentaron al reformismo con el integralismo. En particular, la discusión "libre o laica", referida a la posibilidad de que las universidades privadas, particularmente las ligadas a la Iglesia Católica, expidieran títulos oficiales. Tanto bajo la "Revolución Libertadora", a raíz del artículo 28 del decreto 6.403 que autorizaba la expedición privada de títulos, como durante la presidencia de Frondizi, quien en agosto de 1958 se dispuso a reglamentar dicho decreto, reformistas e integralistas divergieron, ya que estos defendieron la vigencia de la nueva normativa, mientras que los reformistas reivindicaron el monopolio estatal de la educación universitaria. 
tado. A su vez, la nueva dinámica que atravesó al movimiento estudiantil tendió a fortalecer la unidad de acción con el movimiento obrero, las relaciones de cooperación e intercambio de apoyos entre ambos actores, que llegaron a su apogeo en el Cordobazo de 1969.

En el período previo al golpe de Onganía, la agrupación dominante al interior del reformismo, el Movimiento Universitario Reformista (MUR) ligado al PC, entró en tensión con una nueva agrupación, el Movimiento Nacional Reformista (MNR), que, pese a reivindicar el carácter político del reformismo, era contrario al influjo de la política estrictamente partidaria en el movimiento estudiantil. A su vez, en ese marco surgió en Córdoba Franja Morada. De este modo, se comenzó a insinuar un escenario de disputa por la conducción del reformismo, ya que, sobre todo tras la "Revolución Argentina", ninguna agrupación logró tornarse hegemónica. Ello resultó propicio para la propuesta estudiantil del PSIN y su perspectiva de acercamiento entre reformismo y movimiento obrero en clave nacional-popular. Las cuatro entrevistas realizadas a los militantes del PSIN-Córdoba para este trabajo coinciden en observar que su corriente en formación sostuvo una buena relación con el integralismo, de cooperación en acciones de protesta y en asambleas universitarias. Ello ocurrió pese a que no compartieron su postura, originariamente apolítica, de no participar en los centros de estudiantes y las federaciones estudiantiles. Dicha cercanía se basaba en cierta identificación con el nacionalismo popular, en la disposición a protestar en contra de la dictadura y -en relación a la unidad de acción con el movimiento obrero- en el reconocimiento de la legitimidad de la dirigencia sindical peronista cordobesa, aspecto que no compartieron otras corrientes estudiantiles de izquierda, en particular las ligadas a la nueva izquierda marxista, gravitantes con posterioridad al Cordobazo.

Como observamos, el PSIN-Córdoba pudo conformar en el segundo tramo de la década del sesenta un núcleo de activistas estudiantiles con cierta inserción en la casa de estudios más politizada de la provincia: la UNC. Ahora bien, en relación al movimiento obrero, la pata central de la "alianza plebeya", el derrotero del partido fue diferente. La relación del PSIN con el movimiento obrero se desarrolló fundamentalmente desde un acercamiento a sus cúpulas, a partir del diálogo y las acciones de cooperación con la dirigencia sindical, fundamentalmente con la franja peronista. Para ello, fue clave Víctor Hugo Saiz, ya que por la posición de su padre en la CGT provincial y por su militancia en el sindicato de empleados judiciales, pudo establecer un vínculo con la dirigencia sindical, que derivó en acciones de apoyo del PSIN a diversas manifestaciones y protestas impulsadas por el movimiento obrero y permitió que Saiz participara en muchos de los plenarios de la CGT-Regional Córdoba. De este modo, el PSIN construyó un conjunto de vinculaciones con Atilio López, el dirigente de la Unión Tranviaria Automotor (UTA); Raúl Ferreyra y José Phien, del Sindicato de Empleados Públicos (SEP); Miguel Ángel Correa, del Sindicato de la Madera; el abogado laboralista Lucio Garzón Maceda, entre otras figuras relevantes del movimiento obrero provincial. Asimismo, en determinados sindicatos, el PSIN logró ubicar militantes, como es el caso de un núcleo de "juventud 
mercantil" en el Sindicato de Empleados de Comercio y un militante de apellido Segura, en el Sindicato de Molineros, pero sin lograr una inserción relevante. De este modo, el PSIN-Córdoba de 1969 contaba, en la capital provincial, con un núcleo militante predominantemente clasemediero de profesionales y estudiantes universitarios, de alrededor de treinta militantes orgánicos, algunos pocos militantes sindicales, posiblemente cinco o seis, una periferia de simpatizantes en ambas esferas y una buena trama de relaciones con la dirigencia sindical de la provincia. Dicho activo político-militante no era menor si se tiene en cuenta la corta vida del partido y su comienzo con solo cinco miembros de corta edad y experiencia política.

\section{El Cordobazo y el PSIN}

Luego de la caída de Perón, se conformó en Córdoba un nuevo sindicalismo, caracterizado por una serie de rasgos singulares (Brennan y Gordillo, 2008; Mignon, 2013). En primer término, su perfil combativo. Si bien los sindicatos cordobeses de la época se concentraron en problemas gremiales y en la obtención de beneficios para sus afiliados por medio de convenios colectivos, también realizaron numerosas acciones de protesta en articulación con corrientes políticas y estudiantiles y adoptaron posicionamientos públicos referenciados en un ideario de liberación nacional y social, como los vertidos en los programas de La Falda (1957) y Huerta Grande (1962). A su vez, desde diversas posturas ideológicas e intereses sectoriales, los sindicatos cordobeses tendieron a reivindicar una cuota de autonomía respecto de las direcciones centrales radicadas en Buenos Aires. En tal sentido, tanto Alejo Simó, dirigente de la seccional cordobesa de la UOM, como Elpidio Torres, del Sindicato de Mecánicos y Afines del Transporte Automotor (SMATA), debían consolidar su llegada en las bases obreras si querían afianzar su poder, por lo que tendieron a tomar distancia de los acuerdos y directivas emanadas desde las conducciones nacionales de sus sindicatos. Por otra parte, el sector independiente referenciado en Agustín Tosco del sindicato Luz y Fuerza, era contrario al verticalismo peronista, aspecto en el que, en cierto modo, convergía con el peronismo legalista representado por Atilio López de la UTA, receloso del liderazgo de Vandor y proclive a una mayor cercanía con las bases. A su vez, el pluralismo ideológico fue un rasgo de una parte importante del movimiento obrero cordobés, fundamentalmente de los sectores independiente y legalista, y ello logró plasmarse en ciertos acuerdos cupulares, que derivaron en el reparto de cargos en CGT-Regional Córdoba y en una interacción fluida entre todas las vertientes sindicales.

Durante la dictadura de Onganía, luego de un primer momento de diálogo y acercamiento entre los dos principales dirigentes nacionales del peronismo sindical -Augusto Vandor de la UOM y José Alonso del Sindicato del Vestido- y el gobierno, las relaciones entre el movimiento obrero y el gobierno tendieron a deteriorarse. Ello obedeció, entre otras cosas, a la pérdida de salario real que acompañó el "Plan de Estabilización y Desa-

rrollo" lazado por el Ministro de Economía Krieger Vasena en marzo de 1967 y al decreto 
16.936 que limitaba las negociaciones colectivas y el derecho de huelga. A su vez, la política económica del gobierno afectaba actividades específicas como la industria azucarera del norte y al empleo público nacional. De este modo, con motivo del congreso normalizador de la CGT de marzo de 1968, se conformó un nucleamiento sindical opositor, con un planteo de contenido político, liderado por Raimundo Ongaro de la Federación Gráfica Bonaerense, conocido popularmente como la CGT de los Argentinos. La nueva conducción confederal fue desconocida por el sector vandorista en minoría, que pasó a denominarse CGT-Azopardo, de tendencia negociadora con el gobierno.

El planteo antidictatorial y antiimperialista impulsado por Ongaro encontró un fuerte apoyo en las regionales de la CGT del interior del país, en particular en Córdoba, dada la afinidad ideológica con el sector independiente de Tosco. A su vez, en esta provincia, el sector ortodoxo liderado por Simó adoptó una postura "dura", diferenciándose de la inclinación "blanda" de Vandor, y ello se explica, entre otras cosas, por la exclusión de los ortodoxos del interior de las mesas de negociación de Buenos Aires, hecho que alimentó un sentimiento antiburocrático y anticentralista filiado en la resistencia peronista, y por la existencia de demandas propias de las seccionales del interior, desatendidas por las cúpulas nacionales. En este último sentido, se ubicó el reclamo de la UOM-Córdoba respecto de la abolición de las quitas zonales, un mecanismo que perjudicaba salarialmente a sus representados. A su vez, el SMATA-Córdoba, un sindicato líder ubicado en una industria clave como la automotriz, pese a alinearse nacionalmente con el vandorismo, adoptó una fuerte resistencia respecto de los intentos centralizadores de la conducción nacional de su sindicato, en una conducta que refleja la vocación de autonomía que caracterizó al sindicalismo cordobés. En tal sentido, la quita del "sábado inglés", un derecho que permitía a los trabajadores metalmecánicos cobrar durante los sábados el jornal entero efectuando medio día de trabajo, generó un fuerte descontento en este sindicato.

De este modo, un rechazo generalizado por la dictadura, basado tanto en su carácter autoritario y represivo como en el deterioro de las condiciones sectoriales de los trabajadores, estimularon la convocatoria por parte de la CGT-Regional Córdoba de un "paro activo" por 38 horas para el 29 y 30 de mayo de 1969, con movilización hacia el centro de la Ciudad de los principales sindicatos de la provincia: SMATA, Luz y Fuerza, UTA y UOM; a la que se incorporó un movimiento estudiantil altamente movilizado, tal como referimos anteriormente, en un marco de protestas estudiantiles en otras provincias, como las ocurridas en Chaco, Corrientes y Rosario. De este modo, cristalizó una poderosa alianza obrero-estudiantil, concertada en reuniones previas a las jornadas entre dirigentes de ambos sectores, que hizo de la protesta de fines de mayo un punto de inflexión de la historia nacional. Ahora bien, el Cordobazo desbordó la planificación inicial de las dirigencias, y contó con la participación de diversos grupos sociales, por lo que James Brennan y Mónica Gordillo (2008, p. 85) lo definieron como “una protesta popular con un carácter marcadamente obrero, pero también con elementos de una rebelión popular y una insurrección urbana independientes del control de los trabajadores". 
Las entrevistas a militantes realizadas para este trabajo muestran que, durante mayo de 1969, el PSIN-Córdoba dirigió todos sus esfuerzos a radicalizar la protesta obrera y popular e inscribirla en un marco de sentido. En el movimiento estudiantil, ámbito en el que el PSIN tenía mayor gravitación, el partido defendió la postura de unidad obreroestudiantil materializada en la acción conjunta con la CGT. Por lo tanto, en las asambleas generales de centros de estudiantes previas al 29 de mayo, los militantes del AUN, propusieron, en convergencia con representantes de otras corrientes, la moción de movilizarse hacia el centro de la ciudad para confluir con los sindicatos en un gran acto al frente del local de la CGT. Desde esta propuesta confrontaron con el activismo estudiantil ligado a las incipientes formaciones de izquierda marxista y guevarista, que propusieron no asistir a la convocatoria de la CGT para no "hacerle el juego a la burocracia sindical" y movilizarse a barrios periféricos de la ciudad para instar a vecinos a sumarse a la protesta. ${ }^{28}$ La propuesta de AUN y de las corrientes estudiantiles que bregaron por la unidad con el movimiento obrero realmente existente se impuso, pero el carácter desbordante de la protesta extendió la movilización por fuera del centro de la ciudad. ${ }^{29}$

Simultáneamente, durante el mes de mayo, el PSIN redobló sus esfuerzos en la realización de "puerta de fábrica", es decir, la difusión de la línea política del partido entre los trabajadores, al momento de comenzar y/o terminar un turno de trabajo. En esa tesitura, en las vísperas del Cordobazo, el partido difundió su línea política en un manifiesto publicado por La Voz del Interior, el 23 de mayo. Allí, su secretario general, Víctor Hugo Saiz, y su secretario político, Silvio Modazzi, exigieron la restitución de la soberanía popular conculcada en septiembre de 1955 y la constitución de un gobierno obrero y popular que "luche por la soberanía política e independencia económica con justicia social, que sólo será posible con la expulsión del imperialismo y la expropiación de la oligarquía en el marco de la Unidad de los Estados Socialistas de América Latina" . ${ }^{30}$

Durante las jornadas de protesta, el activismo del PSIN persiguió en un primer momento una línea de acción planificada, que luego se desdibujó ante la dinámica desatada. En primera instancia, los militantes del partido se dirigieron al centro de la ciudad, al local de la CGT ubicado en la calle Vélez Sarsfield. En su recorrido se desperdigaron por distintos puntos del centro, a efectos de difundir la consigna "luche, luche, luche y no

\footnotetext{
${ }^{28}$ Tal fue el caso de la agrupación Línea de Acción Popular (LAP) y de los militantes estudiantiles vinculados al PRT-El Combatiente (ERP) (Ferrero, 2009, pp. 194-195). A su vez, la militancia estudiantil vinculada al Partido Comunista Revolucionario (PCR) sostuvo que la huelga de la CGT era funcional a un nuevo golpismo militar contrario a Onganía. A contrapelo, confluyeron en la postura de cooperación con el movimiento obrero AUN, el integralismo, el Frente Estudiantil Nacional (FEN), la militancia estudiantil comunista y el MNR.

${ }^{29}$ Pascual Bianconi, dirigente de AUN, fue destacado por la prensa partidaria no solo por su defensa de la posición de AUN en las asambleas estudiantiles de mayo, sino también por su participación, en calidad de delegado estudiantil, de la asamblea realizada por el SMATA en el Córdoba Sport Club el día 14 de aquel mes, con motivo de la quita del sábado inglés, que resultó disuelta violentamente por la policía. Crónica de la Córdoba Revolucionaria (junio de 1969). Lucha Obrera, 42, reproducido en: Ramos, Spilimbergo, Madariaga, et al. (1974, p. 77).

${ }^{30}$ Socialistas de la Izquierda Nacional se han manifestado ante la ola de violencia (viernes 23 de mayo de 1969). La Voz del interior, reproducido en: Ramos, Spilimbergo, Madariaga, et al. (1974, p. 99).
} 
deje luchar, por un gobierno obrero, obrero y popular", por medio de cánticos y volantes mariposa. Pero con el correr del día el plan inicial se desdibujó y cada uno obró de manera espontánea. En tal sentido, puede destacarse la participación de tres militantes del PSIN -Raúl García, Mario Di Rienzo y Raúl Lagos- los dos primeros de AUN y el tercero de la Juventud Mercantil del PSIN, en el enfrentamiento con la policía montada en la Avenida Vélez Sarsfield al 600, al frente de la terminal vieja de ómnibus, capturado por una fotografía que luego se transformó en icónica del Cordobazo, y la participación en la quema de las oficinas de la empresa estadounidense Xerox, por un militante del PSIN. ${ }^{31}$

Una vez restablecido el control de la situación por parte del Ejército, el PSIN se abocó a difundir una caracterización de lo ocurrido, atravesado por un intenso debate interno. En tal sentido, el Comité Ejecutivo publicó un número especial del periódico partidario en el mes de junio, que, a partir de la crónica de los sucesos y la reivindicación de la participación del partido en los mismos, brindó una caracterización provisoria del Cordobazo en su "Manifiesto de la Izquierda Nacional al Pueblo Argentino", redactado por Ramos. ${ }^{32}$ Allí, se destacó que el bloque de fuerzas nacional-popular, con eje en la clase obrera, obtuvo un triunfo "táctico" que no pudo devenir en "estratégico" por la ausencia de una dirección capaz de darle un vuelco político a la protesta y trasladarlo a la zona metropolitana, donde la "burocracia sindical" -la dirección de la CGT y las federaciones sindicales- capitularon. La ausencia de una dirección política de alcance nacional, para lo que el PSIN evidentemente no se percibía aún capaz, derivó en el carácter "espontáneo" de la protesta. ${ }^{33} \mathrm{El}$ acontecimiento era leído como un parteaguas del ciclo posperonista, en tanto fue el esbozo de una alianza plebeya capaz de aislar al bloque oligárquicoimperialista de sus antiguos aliados en la clase media y de generar una situación prerevolucionaria. El nuevo ciclo socio-político abría la posibilidad de establecer un "gobierno obrero y popular", que realizara la línea programática del PSIN. Evidentemente el PSIN tomaba el partido, en el amplio y heterogéneo espectro de corrientes de izquierda, de la lucha por establecer una interpretación sobre el Cordobazo, acorde a su perspectiva político-ideológica.

\footnotetext{
${ }^{31}$ Di Rienzo, M. (13 de mayo de 2014). Recuerdos de un militante de la Izquierda Nacional, documento inédito cedido al autor por Roberto Ferrero. El día 30 de mayo el Ejército capturó a Saiz en su casa, pese a que este no había participado de las jornadas de protesta, ya que la organización decidió que oficiara de "retén", es decir que se movilizara para defender a los eventuales militantes presos, una vez que cayera la represión. Luego de ello, fue juzgado por la justicia militar del III Cuerpo del Ejército, junto a los principales dirigentes sindicales del Cordobazo, resultando absuelto a los pocos días.

${ }^{32}$ Manifiesto de la Izquierda Nacional al Pueblo Argentino (junio de 1969). Lucha Obrera, 42, reproducido en: Ramos, Spilimbergo, Madariaga, et al. (1974, pp. 105-115).

${ }^{33}$ Es preciso destacar que dicho término no perseguía desconocer el protagonismo de los dirigentes sindicales en el Cordobazo, sino la falta de una dirección política capaz de dar respuesta al conjunto de demandas que allí se expresaron.
} 


\section{Conclusiones}

Partiendo de una aproximación a la identidad ideológica de la IN, este artículo reconstruyó la línea política del PSIN durante el primer tramo de la "Revolución Argentina"; la conformación de este partido político en Córdoba durante los años sesenta, su inserción en el movimiento estudiantil y su vinculación con el movimiento obrero; la partici-

pación de su militancia en el Cordobazo y el significado que la organización construyó en torno a dicho acontecimiento en el período posterior.

Pusimos de relieve la importancia que tuvo el concepto de "alianza plebeya", vinculado a una interpretación específica del fenómeno peronista y la tradición reformista. Vimos cómo, luego, con el correr de los años sesenta, se produjo el crecimiento de la corriente en el movimiento estudiantil de Córdoba, en particular a partir de la creación de AUN en 1968. Por otra parte, nos aproximamos a la relación que el nuevo partido sostuvo con el movimiento obrero provincial. Desde allí avanzamos en la reconstrucción de las prácticas que conformaron la intervención del PSIN en el contexto del Cordobazo.

Creemos que este abordaje enriquece los conocimientos existentes en relación a las izquierdas de los años sesenta, ya que lo consideramos un partido que, en general, está ausente, o al menos ocupa un lugar secundario, en las historizaciones de la izquierda argentina. A su vez, amplía los conocimientos existentes acerca de los ciclos de movilización, al considerar el accionar de un actor específico, un partido político de izquierda. Resta, en ulteriores trabajos, indagar sobre el derrotero nacional y provincial de la organización, en particular cuando esta dio un salto de importancia al conformar el FIP en 1971. Los testimonios aquí recogidos coinciden en observar que allí la IN aumentó sus dimensiones, logró mayor peso en el movimiento estudiantil y acrecentó su visibilidad pública. En ese marco surgen interrogantes acerca de cómo el FIP abordó el ciclo abierto por el Cordobazo, caracterizado por la emergencia de las organizaciones armadas, el sindicalismo clasista y la retirada de la dictadura a partir del Gran Acuerdo Nacional (GAN), de mediados de 1971.

\section{Referencias bibliográficas}

Acha, O. y Eidelman, A. (2000). Nacionalismo y socialismo: Jorge Abelardo Ramos y la “izquierda nacional”. Taller. Revista de Sociedad, Cultura y Política, 13, 100-122.

Acha, O. (2009). Historia crítica de la historiografía argentina. Vol. 1: las izquierdas en el siglo $X X$. Buenos Aires: Prometeo.

Acha, O. (2013). Del populismo marxista al posmarxista: la trayectoria de Ernesto Laclau en la Izquierda Nacional (1963-2013). Archivos de historia del movimiento obrero y la izquierda, 3, 57-78.

Altamirano, C. (2013). Peronismo y cultura de izquierda. Buenos Aires: Siglo XXI.

Balvé, B. y Balvé, B. (1989). El 69. Huelga política de masas: Rosariazo - Cordobazo - Rosariazo. Buenos Aires: Contrapunto. 
135 | El Partido Socialista de la Izquierda Nacional

Brennan, J. y Gordillo, M. (2008). Córdoba rebelde: el Cordobazo, el clasismo y la movilización social. La Plata: De la Campana.

Caruso, V. A. (2018). Intelectuales e izquierda peronista: sus relaciones con la universidad y el movimiento obrero (1955-1973) (Tesis de Doctorado en Historia). Universidad de Buenos Aires: CABA.

Devoto, F. y Pagano, N. (2010). Historia de la historiografía argentina. Buenos Aires: Sudamericana.

Ferrero, R. (2009). Historia crítica del movimiento estudiantil de Córdoba. Tomo III (19551973). Córdoba: Alción Editora.

Ferrero, R. (2010). Alfredo Terzaga: biografía mínima. Córdoba: Ediciones del CEPEN.

Galasso, N. (2007a). Aportes críticos a la historia de la izquierda argentina. Socialismo, peronismo e izquierda nacional (1865-1961). Tomo 1. Buenos Aires: Nuevos Tiempos.

Galasso, N. (2007b). Aportes críticos a la historia de la izquierda argentina. Socialismo, peronismo e izquierda nacional (1961-2001). Tomo 2. Buenos Aires: Nuevos Tiempos.

Georgieff, G. (2008). Nación y revolución. Itinerarios de una controversia en Argentina (19601970). Buenos Aires: Prometeo.

Gordillo, M. (2007). Protesta, rebelión y movilización: de la Resistencia a la lucha armada, 1955-1973. En D. James (Dir.), Nueva historia argentina. Tomo IX Violencia, proscripción y autoritarismo (1955-1976) (pp. 329-380). Buenos Aires: Sudamericana.

Galván, M. V. (2013). El nacionalismo de derecha en la Argentina posperonista. El semanario Azul y Blanco (1956-1969). Rosario: Prohistoria.

Herrera, C. M. (2011). El Partido Socialista de la Revolución Nacional, entre la realidad y el mito. Revista Socialista, 5. URL: http://www.revistasocialista.com.ar/node/90. Descarga: 20/03/2019.

Laclau, E. (2013). Prólogo. En J. A. Ramos, Revolución y contrarrevolución en la Argentina. Tomo V. La era del peronismo (1943-1976) (pp. 9-13). Buenos Aires: Continente.

Mignon, C. (2013). Córdoba Obrera. El Sindicato en la fábrica 1968-1973. Buenos Aires: Imago Mundi.

Ramos, J. A. (1964). La lucha por un partido revolucionario. Buenos Aires: Ediciones Pampa y Cielo.

Ramos, J. A. (1970). Revolución y contrarrevolución en la Argentina. Tomo III - La bella época (1904-1922). Buenos Aires: Ediciones del Mar Dulce.

Ramos, J. A., Spilimbergo, J. A., Madariaga, J. A., et al. (1974). El Cordobazo. Buenos Aires: Octubre.

Regali, E. A. (2012). Abelardo Ramos: la Izquierda Nacional y la Nación Latinoamericana. Córdoba: Ferreyra Editor.

Ribadero, M. (2015). El malestar de una cultura política. La “izquierda nacional” de Jorge Abelardo Ramos ante el frondicismo. Cuadernos de Historia. Serie economía y sociedad, $15,191-227$.

Ribadero, M. (2016). Tiempo de profetas. Ideas, debates y labor cultural de la izquierda nacional de Jorge Abelardo Ramos (1945-1962). Buenos Aires: Bernal.

Anuario de la Escuela de Historia Virtual - Año 10 - N 16 - 2019: pp. 115-136. ISSN 1853-7049 
Roland, E. (2016). Intelectuales y política. Hernández Arregui y la formación de una izquierda argentina (Trabajo Final de Licenciatura en Historia). Universidad Nacional de Córdoba: Córdoba.

Roland, E. (2018). Una aproximación a la mirada de Jorge Enea Spilimbergo sobre el radicalismo. Ponencia presentada en las VII Jornadas de Investigación Científica del Departamento de Historia. Universidad Nacional de Río Cuarto: Río Cuarto.

Sigal, S. (1991). Intelectuales y poder en la década del sesenta. Buenos Aires: Puntosur editores.

Spilimbergo, J. E. (1958). Nacionalismo oligárquico y nacionalismo revolucionario. Buenos Aires: Coyoacán.

Spilimbergo, J. E. (1960). Juan B. Justo o el socialismo cipayo. Buenos Aires: Coyoacán.

Spilimbergo, J. E. (2010 [1964]). Clase obrera y poder. Tesis politicas del tercer congreso del Partido Socialista de la Izquierda Nacional. Buenos Aires: Ediciones del Sur.

Spinelli, M. E. (2005). Los vencedores vencidos. El antiperonismo y la "revolución libertadora". Buenos Aires: Biblos.

Strasser, C. (Ed.) (1959). Las izquierdas en el proceso político argentino. Buenos Aires: Palestra.

Terán, O. (2013). Nuestros años sesenta: la formación de una nueva izquierda intelectual argentina, 1956-1966. Buenos Aires: Siglo XXI Editores.

Terzaga, A. (1974). Rosismo y mitrismo: dos alas de un mismo partido. En J. E. Spilimbergo, A. Terzaga, S. Cabral, L. A. Rodríguez y J. A. Ramos, El revisionismo histórico socialista (pp. 113-130). Buenos Aires: Editorial Octubre.

Terzaga, A. (2010). Emancipación y resistencia en América Latina. Córdoba: Ediciones del Compilador.

Tortorella, R. L. (2012). Los intelectuales en la nación inconclusa. Cultura, historia y política en Jorge Abelardo Ramos. Ponencia presentada en las VII Jornadas de Sociología Universidad Nacional de La Plata: La Plata. URL: http://repositoriosdigitales.mincyt.gob.ar/vufind/Record/MemAca_128653bd09ec7ce2a5d818d575facac1. (Descarga 28/11/19).

Para citar este artículo:

Roland Ernesto (2019). El Partido Socialista de la Izquierda Nacional (PSIN) de Córdoba durante los años sesenta. Su despliegue organizativo y su gravitación en el Cordobazo. Anuario de la Escuela de Historia Virtual 16, pp. 115-136. 